\title{
The Secondary Structure of Human Hageman Factor (Factor XII) and its Alteration by Activating Agents
}

\author{
Carl R. McMilinin, Hidehiko Satto, Oscar D. Ratnoff, and \\ ALAN G. WaLton \\ From the Department of Macromolecular Science, and the Department of \\ Medicine, School of Medicine, Case Western Reserve University, and \\ University Hospitals of Cleveland, Cleveland, Ohio 44106
}

A B S TRACT Hageman factor (factor XII) is activated by exposure to surfaces such as glass or by solutions of certain compounds, notably ellagic acid. Changes in the structure of Hageman factor accompanying activation have been examined in this study by circular dichroism spectroscopy. The spectrum of unactivated Hageman factor in aqueous solutions suggests that its conformation is mainly aperiodic. Various perturbants altered the conformation of Hageman factor in differing ways, demonstrating the sensitivity of Hageman factor to its environment.

After activation of Hageman factor with solutions of ellagic acid, a negative trough appeared in the region of the circular dichroism spectrum commonly assigned to tyrosine residues, along with other minor changes in the peptide spectral region. Some of these changes are similar to changes that occurred upon partial neutralization of the basic residues at alkali pH. Activation of Hageman factor by adsorption to quartz surfaces (in an aqueous environment) also produced changes similar to those in the ellagic acid-activated Hageman factor, including the negative ellipticity in the tyrosine region.

These observations suggest that the activation process may be related to a change in status of some of the basic amino acid residues, coupled with a specific change in the environment of some tyrosine residues. The importance of these changes during the activation process remains to be determined. The sensitivity of Hageman factor to its environment is consistent with the view that the initiation of clotting by exposure of plasma to appropriate agents is brought about by alterations in the conformation of Hageman factor that occur in the

Dr. Ratnoff is a Career Investigator of the American Heart Association.

Received for publication 21 March 1974 and in revised form 22 July 1974. apparent absence of Fletcher factor or other recognized clotting factors.

\section{INTRODUCTION}

Hageman factor ( $\mathrm{HF}^{1}$ factor XII) is a plasma protein needed under appropriate circumstances for the initiation of the intrinsic blood clotting system (1), the formation of a plasma kallikrein from its precursor (2), and the generation of fibrinolytic activity via activation of $\mathrm{HF}$. cofactor (3). The purified protein has a mol wt of approximately 80,000 , but little physical information is available concerning its shape, structure, or mechanism of activation (4-7). Earlier studies have suggested that activation of HF is accompanied by a change from hydrophilic to hydrophobic behavior (7-9).

HF may be activated by adsorption onto certain surfaces, by mixture with some materials in solution, or by fragmentation with proteolytic enzymes such as plasmin and trypsin $(6,10)$. This communication reports studies of the conformation of HF in unactivated and activated states under circumstances designed to shed light on the conformation of this protein and changes in conformation under the influence of perturbants. The method used was transmission circular dichroism (CD), examining adsorbed films in a specially designed cell (11).

\section{METHODS}

Materials. Unactivated $\mathrm{HF}$ was prepared from human oxalated plasma as described recently (12). The preparations used had specific activities of $31-59 \mathrm{U} / \mathrm{mg}$ protein (1 $U$ of HF clot-promoting activity is arbitrarily defined as that amount found in $1 \mathrm{ml}$ of a standard pool of citrate plasma) (4) and contained no measurable amount of

${ }^{1}$ Abbreviations used in this paper: $\mathrm{CD}$, circular dichroism; HF, Hageman factor; $\theta$, ellipticity. 
the other components of clotting, fibrinolytic, or kallikreinkinin systems, as determined by functional assays. The HF was virtually all in the precursor state, the activated form comprising less than $0.2 \%$ of the sample. Upon analytical disk gel electrophoresis (13), two or three very closely associated bands were observed in the $\gamma$ region (Fig. 1), all of which apparently had HF clot-promoting activity as tested by assaying $1-\mathrm{mm}$ segments of replicate gels. Portions were stored in silicone-coated polystyrene containers at $-70^{\circ} \mathrm{C}$ until needed and then dialyzed against $0.15 \mathrm{M} \mathrm{NaCl}$ for at least $4 \mathrm{~h}$ before spectroscopic studies were conducted.

Ellagic acid, synthesized by Dr. James Crum, Case Western Reserve University (14), was dissolved at a concentration of $10^{-4} \mathrm{M}$ in $0.025 \mathrm{M}$ Tris- $\mathrm{HCl}$ buffer ( $\mathrm{pH} 7.5$ ), homogenized, and filtered through Whatman No. 1 paper. The clear filtrate was used, usually in less than $2 \mathrm{~h}$, at room temperature.

$\mathrm{HF}$ fragments were prepared by digesting purified $\mathrm{HF}$ with Enzite-trypsin (Miles Research Div., Miles Laboratories, Inc., Elkhart, Ind.) and separating the resulting fragments on a Sephadex G150 column. The HF fragments had a mol wt of approximately 30,000 , and on analytic polyacrylamide gel electrophoresis three or four bands were observed that migrated in the prealbumin region. These fragments possessed strong prekallikrein-activating activity but only very weak clot-promoting activity, as reported previously $(6,10)$. The $\mathrm{HF}$-fragments were dialyzed against $0.15 \mathrm{M} \mathrm{NaCl}$ before use. The quartz disks used were "far ultraviolet grade," $1 \mathrm{~mm}$ thick and $\frac{1}{2}$ in in diameter (Esco Products, Oak Ridge, N. J.).

$C D$ spectroscopy is a technique that has found extensive application in studies of polypeptide conformation in solution. Many good reviews of the theory and the biological

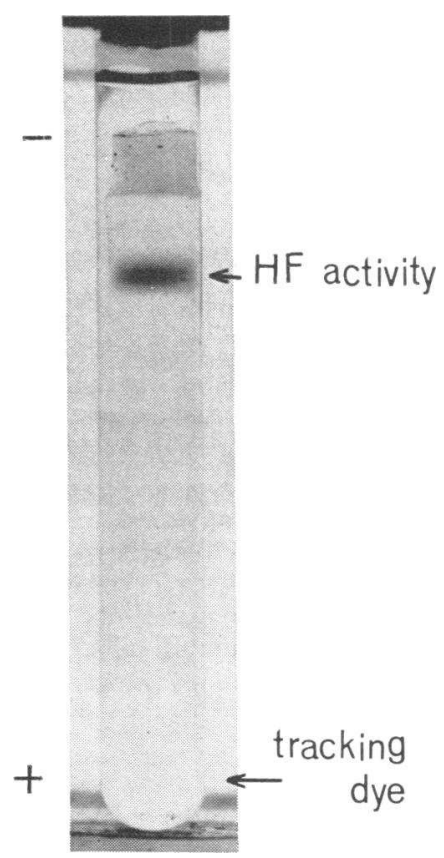

FIGURE 1 Polyacrylamide gel electrophoretic pattern of purified human HF. Two or three closely associated bands are observed in the region, all of which apparently had HFlike clot-promoting activity. (See Methods.)
TABLE I

Approximate Band Positions and Ellipticities for Polypeptidse with Various Conformations

\begin{tabular}{ccc}
\hline Conformation & Wavelength & Ellipticity \\
\hline Alpha helix & $n m$ & deg $\mathrm{cm}^{2} / \mathrm{dmol}$ \\
& 221 & $-30,000$ \\
& 209 & $-30,000$ \\
Beta sheet & 191 & $+60,000$ \\
& 217 & $-20,000$ \\
Extended helix & 195 & $+30,000$ \\
& 238 & -200 \\
& 216 & $+3,300$ \\
& 201 & $-40,000$ \\
& 196 & $+30,000$ \\
Random (proteins) & $\sim 210$ & $-8,000$ \\
& 197 & $-15,000$ \\
\hline
\end{tabular}

Average of some values taken from Ref. 31, 33, 61 and 62 .

applications of CD spectroscopy are in the literature (1521). In essence, the technique measures the difference between the absorption of left- and right-hand circularly polarized light (i.e., light in which the electric vector describes a left- or right-handed spiral as it travels through space) by the substance to be tested.

Ellipticity $(\theta)$ is a measure of this difference in absorption of left- and right-hand circular polarized light and is related to this difference in accordance with the formula $\theta=3,298\left(\epsilon_{\mathrm{L}}-\epsilon_{\mathrm{R}}\right)$, where $\epsilon_{\mathrm{L}}$ and $\epsilon_{\mathrm{R}}$ are the extinction coefficients (i.e., a measure of absorbance of light) of left- and right-hand circularly polarized light.

- Generally, molar extinction coefficients (adsorption per mole of peptide residues) are used in studies of proteins, with the mean (average) $\mathrm{mol} \mathrm{wt}$; hence $[\theta]$ is the mean molar ellipticity.

Since $[\theta]$ changes as a function of the wavelength of the incident radiation, the resultant spectrum consists of a series of bands, which are positive or negative depending on whether $\epsilon_{\mathrm{L}}$ or $\epsilon_{\mathrm{R}}$ is the greater in the specified wavelength range. For polypeptides and proteins the electronic transitions that absorb the incident radiation are located in the ultraviolet region and are recorded on conventional instruments between $\sim 190$ and $\sim 400 \mathrm{~nm}$. The same electronic transitions that give rise to $C D$ bands also absorb unpolarized radiation, giving rise to ultraviolet absorption bands at the same wavelength.

The wavelength, sign (positive or negative), and mean molar ellipticity of the CD bands are known for some specific conformations (i.e., structure of the protein chains). The conformations commonly elucidated for polypeptides are $\alpha$-helix, $\beta$-sheet, extended helix ${ }^{2}$ and random forms. Table I contains information concerning the average band position and molar ellipticity for these conformations obtained

The nomenclature extended helix is used here to describe the conformation of polypeptides and proteins in the left-hand poly-L-proline, polyglycine, and charged helical structures, each of which is said to consist of essentially three peptides per turn of helix and each of which gives a similar CD pattern. 
from a number of sources. It can be seen that all of these bands occur substantially below $250 \mathrm{~nm}$.

The advances made recently in elucidating protein structure by $C D$ have depended heavily on the calibration of this technique by spectroscopy of model synthetic polypeptides and comparison of CD spectra with structural information derived from $\mathrm{X}$-ray diffraction of proteins and polypeptides (22-24). In performing a structural analysis of proteins based on polypeptide information, cognizance must be taken of perhaps four factors that complicate the spectra.

First, proteins generally consist of a polypeptide chain or chains, which contain(s) elements of more than one structure; thus, $\alpha$-helix, $\beta$-sheet, and perhaps extended helix are more or less recognizable (though often distorted). The remainder, and often the predominant chain conformation in proteins, is a fixed structure that is random, in that it follows an irregular path, although it is not the random "freely fluctuating" form of the polypeptide. This portion of a protein is likely to have a $C D$ spectrum similar although not necessarily identical to that of the random polypeptide. $^{3}$ We shall identify this structure as pseudorandom, indicating that it is a unique structure of fixed form but irregular shape.

The second important aspect of $\mathrm{CD}$ analysis of protein structure is the recognition of the presence and behavior of aromatic groups. The side chains of L-tyrosyl, L-phenylalanyl, and L-tryptophanyl residues absorb ultraviolet radiation and contribute to the $C D$ spectrum. Often this contribution is small or negligible, but if the aromatic groups are located in an asymmetric environment or in positions where they can interact either with charged groups or with each other the aromatic contribution can be significant $(37,38)$. The aromatic contribution to a CD spectrum is readily apparent in the spectral region above 225 $\mathrm{nm}$, since polypeptide conformational ellipticity is small or nonexistent in that region. Below $225 \mathrm{~nm}$, however, strong $\mathrm{CD}$ bands associated with peptide groups in $\alpha$-helical and $\beta$-sheet arrays generally obscure the less intense aromatic contributions.

The third aspect of protein structure analysis by $C D$ spectroscopy is that many proteins including bovine HF (39) contain some carbohydrate attached to the polypeptide chains. The main transitions that give rise to $C D$ ellipticity in carbohydrates are located at lower wavelengths than the main polypeptide transitions, and any transitions from the carbohydrate that do occur in the same spectral region are generally weak compared to the polypeptide bands observed $(40,41)$. However, when the carbohydrate content of a protein is high and the overall

- There has been considerable discussion in the literature over the last $5 \mathrm{yr}$ on the nature of the "random" conformation in polypeptides, and which conformational state of synthetic polypeptides should be used as a model for the portions of proteins which have no regular repeating structure. Both theory (25-28) and experimental results for proteins and polypeptides (e.g., 29-32) predict a variety of CD spectra which might be observed for a random optically active polymer. In this paper, in agreement with some recent $C D$, infrared, and laser raman studies (33, $34)$, we assume a random conformation to exist in suitable polypeptides and proteins in high $\mathrm{CaCl}_{2}$ concentrations, and at high temperatures $(35,36)$. These conditions produce only weak negative optical activity above about 215 $\mathrm{nm}$ and a weak negative $C D$ trough around $195 \mathrm{~nm}$.
CD intensity from the polypeptide portion of the molecule is low, contributions to the CD spectrum from the carbohydrate may be significant in the interpretation of the protein spectrum.

The fourth aspect of protein structure inherent in CD analysis is that polypeptide conformations give rise to spectra that correspond to a specific conformation in a defined environment. Often a protein contains distorted conformations that may be buried in a hydrophobic region. Both distortion and location in differing environments may give rise to modifications of the spectral characteristics of a specific conformation $(31,42)$. In addition, it is known that the continuous length of an ordered segment of a protein has a more than proportional effect on the intensity of the CD ellipticity observed (43).

Because of these considerations, one must treat the results of $C D$ analyses of protein structure with caution. Within these limitations, however, useful predictions of protein secondary structure have been made, which correlate fairly well with $\mathrm{X}$-ray diffraction results $(22,23)$. In addition to secondary structure, substantial information relating to denaturation, ionization, binding, and ligand interaction may be deduced by the use of circular dichroism spectroscopy $(37,44,45)$.

The CD spectrum of $H F$ in $0.15 \mathrm{M} \mathrm{NaCl}$ presented in the Results section was obtained as follows: $0.21 \mathrm{ml}$ of $\mathrm{HF}(0.22 \mathrm{mg} / \mathrm{ml}$ in $0.15 \mathrm{M} \mathrm{NaCl})$ was transferred from the polystyrene storage tube to a clean Polybrene-coated (hexadimethrine bromide, Aldrich Chemical Co., Inc., Milwaukee, Wis.) 5-mm jacketed $\mathrm{CD}$ cell with a polystyrene graduated pipette (Falcon Plastics, Oxnard, Calif.) or glass pipette previously rinsed successively with a solution of Polybrene $(2 \mathrm{mg} / \mathrm{ml})$ and distilled water. $0.21 \mathrm{ml}$ of $0.15 \mathrm{M} \mathrm{NaCl}$ was added to the $\mathrm{HF}$ solution and mixed by withdrawing and replacing the solution in the cell with the pipette several times. The cell was placed in the CD machine (JASCO J20 spectropolarimeter with $0.001^{\circ}$ ellipticity maximum sensitivity, Durrum Instrument Corp., Palo Alto, Calif.) and connected to a temperature-controlled methanol/water bath. To record the spectrum below 200 $\mathrm{nm}$, the sample was further diluted to $0.055 \mathrm{mg} / \mathrm{ml}$.

The spectrum of $\mathrm{HF}$ was then analyzed into its component bands with the help of a DuPont 310 Curve Resolver (E. I. DuPont de Nemours \& Co., Wilmington, Del.). In this analysis, we made the assumption that the waveforms were Gaussian and had a width at half height of $14 \mathrm{~nm}$; this width and shape of band fit most of the $\mathrm{CD}$ bands clearly observed between 185 and $250 \mathrm{~nm}$. The bands thus resolved cannot be considered to be the only possible bands that would fit our data, but holding the width constant and decomposing the spectra into the least number of Gaussian curves appeared to give fairly reproducible results. The molar ellipticities and band positions (or wavelengths) for a number of spectra obtained from different lots of HF were averaged, and the tabulated data are presented in the section on Results.

Clean CD cells were obtained by soaking the cells in concentrated sulfuric acid/nitric acid solution $(10: 1)$. The CD cells were then rinsed by passing a running stream of distilled water through the cell for 3 or $4 \mathrm{~min}$ and then dried with dry $\mathrm{N}_{2}$. The dried $\mathrm{CD}$ cells were coated with Polybrene to prevent activation of the HF by the quartz surfaces of the $C D$ cells. The clean $C D$ cells were filled with a $2 \mathrm{mg} / \mathrm{ml}$ solution of Polybrene, emptied, rinsed with a stream of distilled water for 3 or $4 \mathrm{~min}$, and dried with dry $\mathrm{N}_{2}$ 
Acidic and basic $p H$ spectra were obtained by adding a small drop of concentrated hydrochloric acid or sodium hydroxide to the $\mathrm{HF}$ solution. The $\mathrm{pH}$ was measured before and after the $\mathrm{CD}$ recording. The molar ellipticities were calculated with the bands' wavelength and ellipticities as determined by the curve resolver.

The effect of temperature on $H F$ was determined by varying the temperature of $\mathrm{HF}$ in $0.15 \mathrm{M} \mathrm{NaCl}$ from $5^{\circ} \mathrm{C}$ to $90^{\circ} \mathrm{C}$. Spectra were obtained at approximately $5^{\circ}$ increments; the total time spent at each temperature was about $30 \mathrm{~min}$. After reaching equilibrium, usually three scans were made at each temperature. These scans indicated that the sample spectrum did not change with time.

The effect on $H F$ of solvents inducing $\alpha$-helix formation was examined by diluting the $\mathrm{HF}$ solutions (in $0.15 \mathrm{M}$ $\mathrm{NaCl}$ ) with various amounts of trifluoroethanol (Matheson Co., Inc., East Rutherford, N. J.). Methanol was also used to induce $\alpha$-helix formation.

The effect of disrupting the $\alpha$-helical content of $H F$ (in $0.15 \mathrm{M} \mathrm{NaCl}$ ) was examined with the aid of solutions of urea at concentrations ranging up to $6 \mathrm{M}$. Spectra were obtained at intervals of $0.5-1.0 \mathrm{M}$ urea, and molarity was corrected for new total volume.

$H F$ fragments were examined at a concentration of 0.02 $\mathrm{mg} / \mathrm{ml}$ in $0.15 \mathrm{M} \mathrm{NaCl}$. $\mathrm{NaOH}$ was added to obtain a $\mathrm{CD}$ spectrum at $\mathrm{pH} 11.8$.

Solutions of activated $H F$ were prepared by diluting a $10^{-4} \mathrm{M}$ ellagic acid solution in $0.025 \mathrm{M}$ Tris- $\mathrm{Cl}$ buffer $(\mathrm{pH}$ 7.5) with the same buffer to give a $10^{-5} \mathrm{M}$ ellagic acid solution. The solution was then heated to $37^{\circ} \mathrm{C}$, and a base-line $C D$ spectrum was obtained. To $7.5 \mathrm{ml}$ of this solution was added $0.4 \mathrm{ml} \mathrm{HF}$ saline solution $(0.22 \mathrm{mg}$ $\mathrm{HF} / \mathrm{ml}$ ), and the activated $\mathrm{HF} \mathrm{CD}$ spectrum was mea-
TABLE II

Amino Acid Analyses of Human $H F$

\begin{tabular}{|c|c|c|}
\hline $\begin{array}{c}\text { Amino } \\
\text { acid }\end{array}$ & $\begin{array}{l}\text { This } \\
\text { study }\end{array}$ & $\begin{array}{l}\text { Speer } \\
\text { et al. } \\
(47)\end{array}$ \\
\hline & $\%$ & $\%$ \\
\hline Cys & $4.2 \pm 0.8^{*}$ & 0.7 \\
\hline Asp & $6.3 \pm 0.8$ & 8.9 \\
\hline Thr & $5.8 \pm 0.3$ & 8.1 \\
\hline Ser & $8.5 \pm 1.5$ & 10.6 \\
\hline Glu & $11.3 \pm 0.6$ & 11.1 \\
\hline Pro & $8.9 \pm 0.9$ & 5.8 \\
\hline Gly & $10.5 \pm 2.0$ & 13.3 \\
\hline Ala & $9.2 \pm 1.9$ & 7.9 \\
\hline Met & $0.1 \pm 0.1$ & \\
\hline Val & $5.4 \pm 0.4$ & 5.4 \\
\hline Ile & $1.4 \pm 0.1$ & 3.7 \\
\hline Leu & $7.6 \pm 0.9$ & 6.5 \\
\hline Tyr & $2.8 \pm 0.2$ & 2.2 \\
\hline Phe & $2.9 \pm 0.1$ & 3.4 \\
\hline Lys & $4.2 \pm 0.2$ & 6.3 \\
\hline $\mathrm{His}$ & $4.5 \pm 0.8$ & 2.1 \\
\hline Arg & $5.9 \pm 0.5$ & 3.4 \\
\hline
\end{tabular}

The techniques used did not permit estimation of tryptophan. * Standard deviation of three lots of human HF tested.

sured in a $10-\mathrm{cm}$ cell. The activation of $\mathrm{HF}$ was determined by a standard $\mathrm{HF}$ clot-promoting assay by comparing the $10^{-5} \mathrm{M}$ ellagic acid solution to the clot-promoting
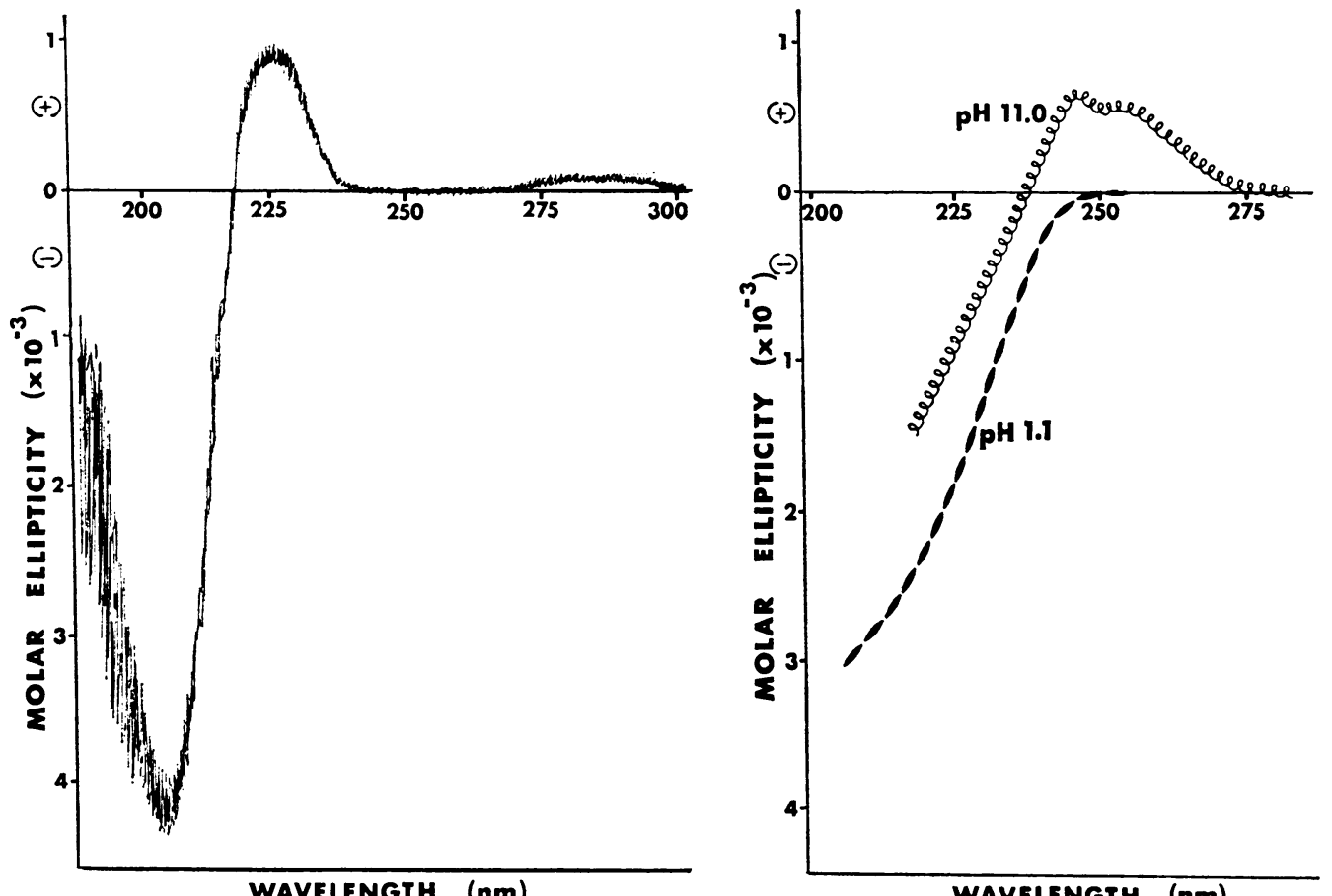

FIgUre 2 Left: A typical solution $\mathrm{CD}$ spectrum of $\mathrm{HF}$ in normal saline solution at $20^{\circ} \mathrm{C}$ and neutral $\mathrm{pH}$. Right: The CD spectrum of $\mathrm{HF}$ under basic conditions of $\mathrm{pH} 11.0$ (ereer) and under acidic conditions of $\mathrm{pH} 1.1$ (- - $)$. 
TABLE III

Average Resolved Band Intensities of $\mathrm{HF}$

\begin{tabular}{|c|c|c|}
\hline Wavelength & \multicolumn{2}{|c|}{ Molar ellipticity } \\
\hline$n m$ & \multicolumn{2}{|c|}{$\operatorname{deg} \mathrm{cm}^{2} / d m o l$} \\
\hline \multicolumn{3}{|c|}{ Solution, neutral $\mathrm{pH}, 20^{\circ} \mathrm{C}$} \\
\hline 257 & $(-)$ & 250 \\
\hline 239 & $(-)$ & 250 \\
\hline 227 & $(+)$ & 960 \\
\hline 216 & $(-)$ & 1,100 \\
\hline 202 & $(-)$ & 4,000 \\
\hline \multicolumn{3}{|c|}{ Solution, pH 1.1} \\
\hline 234 & $(-)$ & 510 \\
\hline 225 & $(-)$ & 640 \\
\hline 217 & $(-)$ & 1,450 \\
\hline 203 & $(-)$ & 3,000 \\
\hline \multicolumn{3}{|c|}{ Solution, $\mathrm{pH} 11.0$} \\
\hline 274 & $(+)$ & 70 \\
\hline 259 & $(+)$ & 310 \\
\hline 243 & $(+)$ & 520 \\
\hline 237 & $(-)$ & 370 \\
\hline 221 & $(-)$ & 1,000 \\
\hline \multicolumn{3}{|c|}{ Solution, ellagic acid activated } \\
\hline 299 & $(-)$ & 230 \\
\hline 289 & $(-)$ & 530 \\
\hline 265 & $(+)$ & 390 \\
\hline 253 & $(+)$ & 460 \\
\hline 226 & $(+)$ & 600 \\
\hline 215 & $(-)$ & 800 \\
\hline \multicolumn{3}{|c|}{ Adsorbed, dry } \\
\hline 279 & $(-)$ & 220 \\
\hline 239 & $(-)$ & 260 \\
\hline 228 & $(-)$ & 750 \\
\hline 217 & $(-)$ & 1,600 \\
\hline 204 & $(-)$ & 3,700 \\
\hline \multicolumn{3}{|c|}{ Adsorbed, under water } \\
\hline 275 & $(-)$ & 220 \\
\hline 243 & $(+)$ & 750 \\
\hline 232 & $(+)$ & 640 \\
\hline 217 & $(+)$ & 700 \\
\hline 205 & $(-)$ & 1,050 \\
\hline \multicolumn{3}{|c|}{ Solution, trifluoroethanol (15\%) } \\
\hline 237 & $(-)$ & 380 \\
\hline 227 & $(-)$ & 2,000 \\
\hline 218 & $(-)$ & 4,000 \\
\hline 205 & $(-)$ & 7,700 \\
\hline
\end{tabular}

ability of various dilutions of $\mathrm{HF}$ measured in the presence of kaolin (4).

Clean quartz disks were obtained by placing the disks in a concentrated $\mathrm{H}_{2} \mathrm{SO}_{4} / \mathrm{HNO}_{3}$ solution for several moments. Distilled water was added slowly while this solution was mixed. The disks were then rinsed in a stream of distilled water for 3 or $4 \mathrm{~min}$. The disks were dried with paper towels, and the entire procedure was repeated. If a nonprotein polymer had been in contact with the disks, acetone was substituted for the $\mathrm{H}_{2} \mathrm{SO}_{4} / \mathrm{HNO}_{3}$ in the above procedure between the two acid treatments.

Adsorbed $H F$ was prepared by immersing the clean quartz disks (usually 15 disks) one at a time in $0.3 \mathrm{ml}$ of $\mathrm{HF}$ solution $(0.22 \mathrm{mg} / \mathrm{ml}$ in $0.15 \mathrm{M} \mathrm{NaCl})$. After approximately $15 \mathrm{~s}$, the disks were removed and submerged 6-10 times in 1 liter of distilled water. The disks were then dried either with dry $\mathrm{N}_{2}$ or by evaporation on their edges on a paper towel.

Adsorbed spectra of $H F$ were obtained by using 15 quartz disks (30 surfaces) to which HF had been adsorbed. Since there was variation in the size of the quartz disks and in the grooves of the Teflon disk holder, care was required to match the quartz disks with grooves that would hold the disks perpendicular to the light beam of the $C D$ machine to reduce depolarization and scattering and yet not apply such pressure as to induce stress birefringence. The disks were selected to fit the grooves in such a way that only light pressure was required to insert the disks in the cell and the disks would not fall out of the cell when it was inverted and tapped lightly. A detailed description of the multidisk system has been presented earlier (11).

This cell, with disks in place, was then placed in the CD beam and scanned from $325 \mathrm{~nm}$ to $290 \mathrm{~nm}$ (a region where there should be zero optical activity). If the CD on highest sensitivity $(0.001 \%) \mathrm{cm})$ showed less than $1 \mathrm{~cm}$ and preferably less than $0.5 \mathrm{~cm}$ displacement throughout this region, the intrinsic birefringence of the disks was assumed to be zero, and the CD spectrum of the adsorbed protein was measured. If greater than $1 \mathrm{~cm}$ displacement occurred, the disks were emptied from the cell and reinserted into different grooves until a flat base line at high wavelength was obtained.

To obtain the wet (partially solvated) adsorbed HF spectrum, the end retaining plates (including quartz disk windows) were attached to the cell with the disks in place. A spectrum was run in this condition to assure that no additional stresses had been placed on the system. The cell was then filled with distilled water or $0.15 \mathrm{M} \mathrm{NaCl}$, and the wet adsorbed spectrum was obtained. The fluid was then emptied, and the disks, still in the cell, were dried with $\mathrm{N}_{2}$, and another dry spectrum was measured to assure that no protein had been desorbed into the solution. These spectra were then analyzed with the DuPont 310 Curve Resolver to determine the position and intensity of the component $\mathrm{CD}$ bands. The resolved positions and intensities from several spectra were then averaged. Again with the curve resolver, the averaged bands were recombined to give the spectrum presented.

The amino acid analyses of $H F$ were carried out with a Durrum D500 Amino Acid Analyser (Durrum Instruments). The amino acid analysis of HF given (Table II) is the average of analyses performed on three different lots of $\mathrm{HF}$. Two lots of $50 \mu \mathrm{g} \mathrm{HF} \mathrm{(52} \mathrm{and} 59 \mathrm{U} / \mathrm{mg}$ ) were dissolved in $0.5 \mathrm{ml} 0.15 \mathrm{M} \mathrm{NaCl}$ and brought to $6 \mathrm{~N}$ with hydrochloric acid. These samples were flushed with nitrogen in a sealed tube and heated at $80^{\circ} \mathrm{C}$ for $10 \mathrm{~h}$ in a heated oil temperature block. The samples were then subjected to a vacuum for $24 \mathrm{~h}$ with a mechanical oil pump, and lyophilized from the frozen state. The samples were dissolved in $100 \mu \mathrm{l}$ of $\mathrm{Na}$ citrate buffer ( $\mathrm{pH} 2.2$ ), the backup buffer for the amino acid analyzer, and centrifuged in a Beckman 152 microfuge. 20- $\mu 1$ samples were loaded into the analyzer. The computer print-out was in 

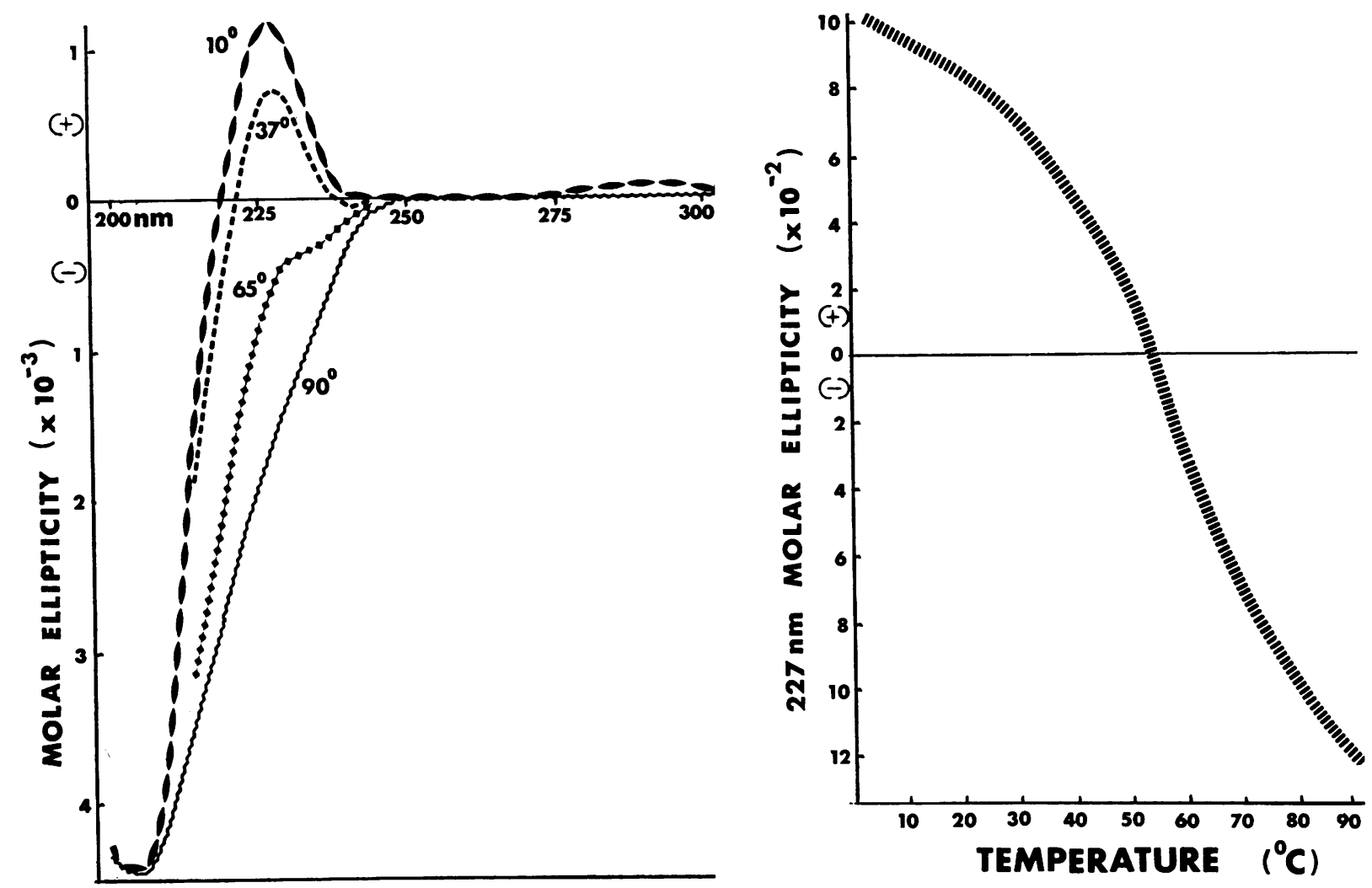

\section{WAVELENGTH $(\mathbf{n m})$}

Figure 3 Left: The $\mathrm{CD}$ spectrum of $\mathrm{HF}$ at neutral $\mathrm{pH}$, normal saline solution at $10^{\circ} \mathrm{C}$

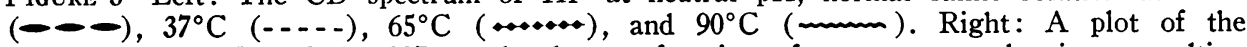
molar ellipticity $[\theta]$ of the $227 \mathrm{~nm}$ band as a function of temperature, showing a melting temperature (i.e. the temperature at which the ellipticity of the $227 \mathrm{~nm}$ band is midway between its maximum and minimum ellipticity) of approximately $53^{\circ} \mathrm{C}$.

nanomoles of each amino acid; these values were converted to percentages. Since tryptophan is destroyed by acid hydrolysis and since some cysteine is converted to cysteic acid, no value for tryptophan is reported, and the cysteine value reported is the sum of the cysteine and cysteic acid found after the acid hydrolysis.

The third lot $(0.15 \mathrm{mg}$ of $53 \mathrm{U} / \mathrm{mg} \mathrm{HF}$ in $0.5 \mathrm{ml}$ barbital-saline buffer containing $10^{-4} \mathrm{M}$ EDTA) was hydrolyzed in $6 \mathrm{~N}$ hydrochloric acid, lyophilized, dissolved, centrifuged, and relyophilized (Microbiological Labs, Inc. Maple Heights, Ohio). It was then dissolved in $150 \mu$ $(1.0 \mathrm{mg} / \mathrm{ml})$ of lithium citrate backup buffer $(\mathrm{pH} \mathrm{2.2)}$, and 20- $\mu 1$ samples were assayed on the amino acid analyzer.

Assays of clotting, fibrinolytic, and kallikrein-kinin components were performed as summarized recently (46).

\section{RESULTS}

Amino acid analysis of human $H F$. The average amino acid analysis of the three lots of human HF is given in Table II, along with the associated SD for each value. The average SD was found to be $0.71 \%$. Also listed for comparison are the values previously published for the amino acid analysis of human HF by Speer, Ridgway, and Hill (47). We agree on the large number of charged residues present, but discrepancies in the amounts of several residues, most notably cysteine, were observed.

Solutions of unactivated $H F$. A typical CD spectrum of $\mathrm{HF}$ in $0.15 \mathrm{M} \mathrm{NaCl}$ solution at neutral $\mathrm{pH}$ and $20^{\circ} \mathrm{C}$ is shown in Fig. 2. The general shape and intensity of the curve indicated a large pseudorandom component in the protein. Analysis of many such spectra of $\mathrm{HF}$ revealed six resolvable $C D$ bands, as indicated in Table III. Below $250 \mathrm{~nm}$, only the 227 band was positive in ellipticity. The overall intensity of the protein conformational bands was low, with a maximum intensity of around $4,000 \mathrm{deg} \mathrm{cm}^{2} / \mathrm{dmol}$ for the $202 \mathrm{~nm}$ band (calculated with a mean residue mol wt of 106 as determined by amino acid analysis).

The spectrum changed at both basic and acidic $\mathrm{pH}$, as shown in Fig. 2. Under acidic conditions, the $227 \mathrm{~nm}$ band had a negative ellipticity, while the rest of the spectrum remained essentially the same as the neutral spectrum. The $\mathrm{CD}$ spectrum of $\mathrm{HF}$ at basic pH, Fig. 2, displayed positive bands around 237,243 , and $259 \mathrm{~nm}$. 


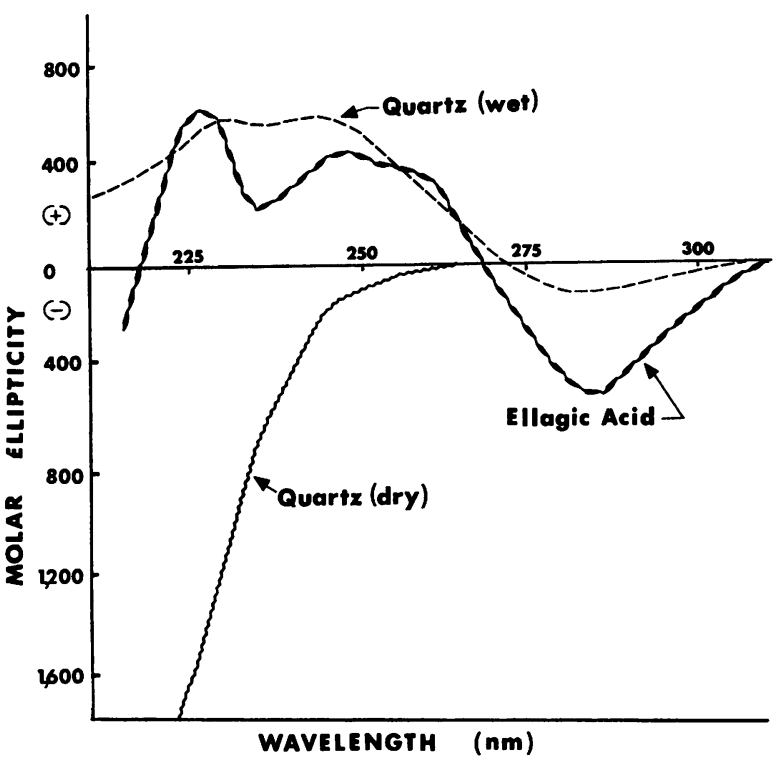

FIgURE 4 The CD spectra of "activated" HF under differing conditions, each of which may be argued to be the "activated" HF spectrum. These are: $10^{-5} \mathrm{M}$ ellagic acid solution of HF ( $\sim$ ), adsorbed monolayers of $\mathrm{HF}$ on quartz-dry ( quartz with the monolayers in contact with water (--- ).

The effect of elevated temperature is generally to cause partial or total denaturation of protein structure. For $\mathrm{HF}$, an increase in temperature to $90^{\circ} \mathrm{C}$ caused a gradual dimunition of the $227 \mathrm{~nm}$ band like that caused by the decrease in $\mathrm{pH}$ (Fig. 3), with the high-temperature spectrum containing a negative $227 \mathrm{~nm}$ band. Even at $95^{\circ} \mathrm{C}$, however, the ellipticity of the negative trough at $202 \mathrm{~nm}$ remained constant or perhaps became enhanced, and red shifted slightly. From $10^{\circ}$ to $20^{\circ} \mathrm{C}$, but not at $37^{\circ} \mathrm{C}$, a small positive ellipticity $([\theta] \cong 130)$ was observed in the 275-300 nm region of the CD spectra.

Addition of a solvent that induced $\alpha$-helix formation, trifluoroethanol, $15 \%$ by volume, produced a spectrum with a negative $227 \mathrm{~nm}$ band as well as negative bands at 205 and $218 \mathrm{~nm}$ (Table III). Although less than 15\% trifluorethanol was required to perturb the $C D$ spectrum of $\mathrm{HF}$, more than $25 \%$ methanol (a weaker $\alpha$-helixinducing solvent) was required to produce similar changes in the spectrum.

A study was conducted on $\mathrm{HF}$ to ascertain its reaction to urea, classically used to denature proteins (48, 49 ), although there is still a controversy concerning the true action of urea on polypeptides and proteins (34). Addition of up to $6 \mathrm{M}$ urea did not change significantly the $C D$ spectrum obtained, that is to say, the positive $227 \mathrm{~nm}$ band did not disappear nor did that portion of the $202 \mathrm{~nm}$ trough which could be observed.

Ellagic acid-activated hageman factor. The CD spec- trum of an ellagic acid-activated HF solution is shown in Fig. 4. $10^{-s} \mathrm{M}$ ellagic acid in Tris- $\mathrm{Cl}$ buffer was about $20 \%$ as effective as incubation with kaolin (10 $\mathrm{mg} / \mathrm{ml}$ ), measured in the clot-promoting assay, in the activation of HF. Ellagic acid, although having absorption bands at $253 \mathrm{~nm}$ and $276 \mathrm{~nm}$, has no optical activity and thus no $C D$ spectrum in the regions examined. The ellagic acid-activated $\mathrm{HF}$ spectrum differed from that of normal unactivated HF mainly in the high wavelength region (Table III), where bands appeared at $299(-), 289(-), 265(+)$, and $253(+) \mathrm{nm}$. In addition, the $227 \mathrm{~nm}$ band was slightly decreased in ellipticity.

Trypsin-activated $H F$ (fragments). The HF fragments produced a CD spectrum in which negative troughs occurred at $235 \mathrm{~nm}$ as well as around $202 \mathrm{~nm}$. The negative trough at $235 \mathrm{~nm}$ became increasingly negative as the $\mathrm{pH}$ was raised, ranging from $[\theta]=$ -920 at $\mathrm{pH} 7.2$ to $[\theta]=-3,200$ at $\mathrm{pH} 11.8$.

Surface-activated Hageman factor. Adsorbed monolayers of $\mathrm{HF}$ were prepared on quartz discs and were examined in the multidisk CD cell in both the dry and wet (partially solvated) states. Earlier studies have indicated that approximately a monolayer of protein adhered to each exposed surface (11), in agreement with the results of previous ellipsometry experiments $(50,51)$. Wet films were examined in the presence of water or aqueous saline solution.

Although the spectra of the dry and wet adsorbed HF differed, these differences did not represent irreversible conformational changes. Thus, when the wet preparation was dried, its spectrum reverted to that of the dry HF and vice versa. These observations also indicated that none of the adsorbed protein was released into solution while it was in the wet state. The two spectra are illustrated in Fig. 4. In the dry state, the major change in the spectrum compared with the solution spectrum was the disappearance of the $227 \mathrm{~nm}$ band. The effect was thus similar to that produced by elevated temperatures, acidic $\mathrm{pH}$, or fragmentation of $\mathrm{HF}$ by trypsin. In the wet spectra of adsorbed HF, however, two positive bands (232 and $244 \mathrm{~nm}$ ) and a negative band $(275 \mathrm{~nm})$ occurred at high wavelengths, while there appeared to be a decrease in the troughs at 202 and $216 \mathrm{~nm}$ (Table III).

\section{DISCUSSION}

Studies of the conformation of Hageman factor, utilizing $C D$ spectroscopy, demonstrate changes upon activation of this factor by quartz surfaces or by solutions of ellagic acid. The observed changes in CD spectra during activation, evidence that conformational changes have occurred, may be interpreted in several ways.

Unactivated HF spectra. The CD spectrum of HF in $0.15 \mathrm{M} \mathrm{NaCl}$ at neutral $\mathrm{pH}$ at $37^{\circ} \mathrm{C}$ or less had a low 
overall ellipticity, suggesting that the protein has a low content of regular structure. It may be concluded, therefore, that the protein was predominantly in a pseudorandom conformation.

An important feature of the CD spectrum of unactivated $\mathrm{HF}$ was a positive band at $227 \mathrm{~nm}$, in contradistinction to most globular proteins. The origin of this band is not clear. Three possible sources of a $227 \mathrm{~nm}$ band in spectra of $\mathrm{HF}$ are aromatic residues, most likely tyrosine, chromophores associated with carbohydrate groups, or the polypeptide secondary structure of the HF molecule. A clear choice among these possibilities cannot yet be made.

Tyrosyl groups are known to display a CD band at $227 \mathrm{~nm}$. When solutions containing tyrosine are made basic, this tyrosine band shifts toward the red, and other tyrosine bands, observed at higher wavelengths, are also altered $(52,53)$. It is possible that tyrosyl groups are responsible for the $227 \mathrm{~nm}$ band observed in unactivated $\mathrm{HF}$. But less than $3 \%$ of the residues of this protein were tyrosine, despite the relatively high molar ellipticity observed at $227 \mathrm{~nm}$. Further, when HF was adsorbed to quartz disks and dried or was examined in solution at high temperatures or acidic $\mathrm{pH}$ 's a negative $227 \mathrm{~nm}$ band was observed. In contrast, studies of model compounds containing tyrosine have always displayed a positive $227 \mathrm{~nm}$ band $(18,54,55)$. Thus, evidence that tyrosine groups are responsible for the $227 \mathrm{~nm}$ band is equivocal. Because other aromatic residues and cysteine could also contribute to the $\mathrm{CD}$ spectrum in this region (15), the possibility that the $227 \mathrm{~nm}$ band arose from a combination of these agents cannot be ruled out.

Bovine Hageman factor contains about $15 \%$ carbohydrate (39), and chromophores associated with carbohydrates can have electronic transitions in the vicinity of $227 \mathrm{~nm}(16,40,41)$. The molar ellipticity of these carbohydrate bands is usually weaker than that observed in this region in studies of HF. Further, we are not familiar with conditions which would change the sign of ellipticity of such carbohydrate chromophores as is observed for HF. Thus, no substantial evidence suggests a role for carbohydrate chromophores in the genesis of the $227 \mathrm{~nm}$ band.

A third possible source for the $227 \mathrm{~nm}$ band is the polypeptide secondary structure of the $\mathrm{HF}$ molecule. One possible structure, the polyproline II conformation, a 31 helix (that is, a helix with 3 residues per turn) that exists in some fibrous proteins, has a positive elipticity of $3,300 \mathrm{deg} \mathrm{cm}^{2} / \mathrm{dmol}$ at $226 \mathrm{~nm}$. The observed $1000 \mathrm{deg} \mathrm{cm}^{2} / \mathrm{dmol}$ ellipticity of the $227 \mathrm{~nm}$ band in $\mathrm{HF}$ would require that this protein contain a substantial quantity of proline were this structure present, but HF in fact contained only $9 \%$ proline. In addition, this structure has not been observed in those globular proteins in which the secondary structure is known by $\mathrm{X}$-ray diffraction.

It has been suggested recently that poly-L-lysine in its charged form and other noncharged polypeptides that display a positive band at about $217 \mathrm{~nm}$ exist in a loosely organized conformation with short range order resembling a 31 helix $(33-36,56,57)$. Charge repulsion contributes to the stability of this conformation in some of these polypeptides. In view of the high content of charged residues in $\mathrm{HF}$ ( $30 \%$ basic and acidic residues), the possibility exists that a charge-stabilized conformation occurs in HF. Thus, the two polypeptide conformations known to produce a positive $\mathrm{CD}$ band in the 227 $\mathrm{nm}$ region of the spectrum are both related to a $3 \mathbf{1}$ helix.

A charge-stabilized conformation could account for the observed properties of the $227 \mathrm{~nm}$ band, independent of the presence of tyrosyl groups. The molar ellipticity of the $227 \mathrm{~nm}$ band is consistent with the interpretation that approximately $30 \%$ of the residues are in this conformation. If this conformation exists, it is apparently very sensitive to its environment. Thus, the conformation was destroyed by neutralization of its charges by shifting the $\mathrm{pH}$ to acidic or basic regions. Further, it was destroyed by nonaqueous solvent, by removing solvents, and by fragmentation with trypsin and heating. On the other hand, the addition of $6 \mathrm{M}$ urea did not appear to affect the $227 \mathrm{~nm}$ band, an observation that could be consistent with the presence of this conformation (35). A stumbling block to this interpretation is that the position of the band, $227 \mathrm{~nm}$, was about $10 \mathrm{~nm}$ higher than that usually reported for charged polypeptides.

At higher wavelengths, at which electronic transitions attributed to aromatic amino acid residues usually take place, only minimal optical activity was noted at the concentrations of $\mathrm{HF}$ tested. This indicated that the aromatic residues ( $5.6 \%$ of $\mathrm{HF}$ ) were probably in positions in which their electronic structures were not greatly perturbed by their environment, as might be true if they were in the random portions of the molecule $(37,58)$ or buried within the interior of the molecule (15). At basic pH's, the aromatic portion of the CD spectrum of $\mathrm{HF}$ showed greater ellipticity than at neutrality, indicating that ionization had occurred and that a slightly different environment for the aromatic residues may have existed under these conditions.

The activation of $H F$. The crux of the present study was the demonstration that activation of $\mathrm{HF}$ was accompanied by a change in the $C D$ spectrum, which suggested that conformational changes occurred during this

\footnotetext{
- Painter, P., and J. L. Koenig. 1974. The solution conformation of poly-L-lysine: raman and infrared spectorscopic study. Submitted to Biopolymers.
} 
process. Both ellagic acid-activated and quartz-activated HF showed larger aromatic ellipticities than those observed with unactivated $\mathrm{HF}$ or with a mixture of amino acids in the same ratio and concentration as in $\mathrm{HF}$. Spectra of trypsin-activated HF (HF fragments), which were very weak clot-promoters but were strong activators of kinin-generating systems, demonstrated little optical activity in the aromatic region. The difference between the aromatic ellipticity in activated and unactivated $\mathrm{HF}$ probably reflected a change in the environment of some of the aromatic residues in this protein. This change in environment may have been related to increased hydrophobic behavior of activated $\mathrm{HF}$ reported earlier $(7,8)$. At low temperatures, a small aromatic band was observed that could not be discerned at $37^{\circ} \mathrm{C}$ (Fig. 3). Armstrong (59) has reported that the kinin-generating system may become spontaneously activated at low temperatures.

A tentative conclusion of the present studies, then, is that the conformation and conformational transitions of $\mathrm{HF}$ are susceptible to study by $\mathrm{CD}$ spectroscopy. $\mathrm{HF}$ appeared to have little or no $\alpha$-helix or $\beta$-sheet conformation and was very sensitive to many perturbants. Our preparations of HF appeared to contain either some charge-stabilized structure, possibly on the surface of the molecule, or a tyrosine band with unusual properties. Upon activation, HF underwent a change in its conformation, and in this state, a change in the environment of some of its aromatic residues, most likely tyrosine, took place. The CD spectrum of trypsin-induced HF fragments differed from those of activated and unactivated $\mathrm{HF}$, suggesting still greater changes had taken place.

For many years, Hageman factor has been believed to be the first protein involved in blood coagulation. However, it has also been suggested recently that Fletcher factor may act before Hageman factor in the clotting of blood $(5,60)$, although we have expressed contrary views (12). This study has shown that $\mathrm{HF}$ has a secondary structure that is easily perturbed in the absence of Fletcher factor by many conditions, including activation by ellagic acid and quartz surfaces. Other studies, still in progress, have indicated that both PTA and kallikrein have secondary structures that are not easily perturbed and are similar in many respects to $\gamma$-globulin and other globular proteins. These observations are in harmony with the view that activation of $\mathrm{HF}$ is brought about by changes in its conformation upon contact with surfaces.

We must stress that this conformational analysis, relying only upon the evidence of $\mathrm{CD}$, is only a "most probable" hypothesis based on our current, still limited understanding of the relation between protein structure and $C D$ spectra.

\section{ACKNOWLEDGMENTS}

This work was supported in part by Research Grant HL 01661 from the National Heart and Lung Institute, the National Institutes of Health, U. S. Public Health Service, and in part by grants from the American Heart Association.

\section{REFERENCES}

1. Ratnoff, O. D., and J. M. Rosenblum. 1958. Role of Hageman factor in the initiation of clotting by glass: evidence that glass frees Hageman factor from inhibition. Am. J. Med. 25: 160-168.

2. Margolis, J. 1958. Activation of plasma by contact with glass: evidence for a common reaction which releases plasma kinin and initiates coagulation. J. Physiol. $144: 1-22$.

3. Niewiarowski, S., and O. Prou-Wartelle. 1959. Role du facteur contact (Facteur Hageman) dans la fibrinolyse. Thromb. Diath. Haemorrh. 3: 593-603.

4. Ratnoff, O. D., and E. W. Davie. 1962. The purification of activated Hageman factor (activated factor XII). Biochemistry. 1: 967-975.

5. Cochrane, C. G., S. D. Revak, and K. D. Wuepper. 1973. Activation of Hageman factor in solid and fluid phases. J. Exp. Med. 138: 1564-1583.

6. Cochrane, C. G., and K. D. Wuepper. 1971. The first component of the kinin-forming system in human and rabbit plasma. Its relationship to clotting factor XII (Hageman factor). J. Exp. Med. 134: 986-1004.

7. Donaldson, V. H., and O. D. Ratnoff. 1965. Hageman factor: alterations in physical properties during activation. Science (Wash. D. C.). 150: 754-756.

8. Vroman, L. 1965. A resemblance between clotting of blood plasma and the breakdown of cytoplasm. Nature (Lond.). 205 : 496-497.

9. Margolis, J. 1963. The interrelationship of coagulation of plasma and release of peptides. Ann. N.Y. Acad. Sci. 104: 133-145.

10. Kaplan, A. P., and K. F. Austen. 1971. A prealbumin activator of prekallikrein. II. Derivation of activators of prekallikrein from active Hageman factor by digestion with plasmin. J. Exp. Med. 133: 696-712.

11. McMillin, C. R., and A. G. Walton. 1974. A circular dichroism technique for the study of adsorbed protein structure. J. Colloid Interface Sci. 48: 345-349.

12. Saito, H., O. D. Ratnoff, and V. H. Donaldson. 1974. Defective activation of clotting, fibrinolytic, and permeability-enhancing systems in human Fletcher trait plasma. Circ. Res. 34: 641-651.

13. Davies, B. J. 1964. Disc electrophoresis. II. Method and application to human serum protein. Ann. N. Y. Acad. Sci. 121 : 404-427.

14. Ratnoff, O. D., and J. D. Crum. 1964. Activation of Hageman factor by solutions of ellagic acid. J. Lab. Clin. Med. 63 : 359-377.

15. Beychok, S. 1967. Circular dichronism of poly- $\alpha$-amino acids and proteins. In Poly- $\alpha$-amino Acids. G. D. Fasman, editor. Marcel Dekker, Inc., New York. Series I. 293-337.

16. Bush, C. A. 1971. Optical rotatory dispersion and circular dichroism. Phys. Tech. Biol. Res. Optical Tech. 2nd edition. $1: 347-408$.

17. Adler, A. J., N. J. Greenfield, and G. D. Fasman. 1973. Circular dichroism and optical rotatory dispersion of proteins and polypeptides. Methods Enzymol. 27: 675735. 
18. Sears, D. W., and S. Beychok. 1973. Circular dichroism. In Physical Principles and Techniques of Protein Chemistry. S. S. Leach, editor. Academic Press, Inc., New York. 445-585.

19. Ramachandran, G. N. 1967. Conformation of Biopolymers. Academic Press, New York. 425.

20. Martin, A. R. 1973. Spectroscopic methods in biology with application to neurophysiology. Adv. Biol. Med. Phys. 14: 225-284.

21. Bayley, P. M. 1973. The analysis of circular dichroism of biomolecules. Prog. Biophys. Mol. Biol. 27: 3-76.

22. Chen, Y.-H., J. T. Yang, and H. M. Martinez. 1972. Determination of the secondary structure of proteins by circular dichronism and optical rotatory dispersion. Biochemistry. $11: 4120-4131$.

23. Saxena, V. P., and D. B. Wetlaufer. 1971. A new basis for interpreting the circular dichronism specta of proteins. Proc. Natl. Acad. Sci. U. S. A. 68: 969-972.

24. Stevens, L., R. Townend, S. N. Timasheff, G. D. Fasman, and J. Potter. 1968. The circular dichroism of polypeptide films. Biochemistry. 7: 3717-3720.

25. Ronish, E. W., and S. Krimm. 1972. Theoretical calculation of the circular dichroism of unordered polypeptide chains. Biopolymers. 11: 1919-1928.

26. Madison, V., and J. Schellman. 1972. Optical activity of polypeptides and proteins. Biopolymers. 11: 10411076.

27. Aebersold, D., and E. S. Pysh. 1970. Optical properties of amorphous polypeptides. I. One state solutions. $J$. Chem. Phys. 53: 2156- 2163.

28. Tonelli, A. E. 1969. The calculated rotatory properties of random-coil poly-L-alaime. Macromolecules. 2: 635637.

29. Chen, Y.-H., and J. T. Yang. 1971. A new approach to the calculation of the secondary structures of globular proteins by optical rotatory dispersion and circular dichroism. Biochem. Biophys. Res. Commun. 44: 12851291.

30. Carver, J. P., E. Shechter, and E. R. Blout. 1966. Analysis of the optical rotatory dispersion of polypeptides and proteins. J. Am. Chem. Soc. 88: 2550.

31. Timasheff, S. N., H. Susi, R. Townend, L. Stevens, M. Gorbunoff, and T. F. Kumosinski. 1967. Int. Symp. Conform. Biopolym. 1: 173-196.

32. Epand, R. M., G. E. Wheeler, and M. A. Moscarello. 1974. Circular dichroism and proton magnetic resonance studies of random chain poly-L-lysine. Biopolymers. 13: 359-369.

33. Ho, R. 1974. The circular dichroism of $3_{1}$ helix-random coil transition of polypeptides in solution. M.S. Thesis. Department of Chemistry, Case Western Reserve University, Cleveland, Ohio.

34. Tiffany, M. L., and S. Krimm. 1974. Poly-N-(3-hydroxypropyl)-L-glutamine as a model system in circular dichroism studies of the interaction of salts with proteins. Fed. Proc. 33 : 1305. (Abstr.)

35. Tiffany, M. L., and S. Krimm. 1973. Extended conformations of polypeptides and proteins in urea and guanidine hydrochloride. Biopolymers. 12 : 575-587.

36. Tiffany, M. L., and S. Krimm. 1969. Circular dichroism of the "random" polypeptide chain. Biopolymers. 8: 347-359.

37. Gratzer, W. B., and D. A. Cowburn. 1969. Optical activities of biopolymers. Nature (Lond.). 222: 426431.

38. Rosenberg, A. 1966. The optical rotatory dispersion of aromatic amino acids and the side chain-dependent cotton effects in proteins. J. Biol. Chem. 241: 51195125.

39. Schoenmakers, J. G., R. Matze, C. Haanen, and F. Zilliken. 1965. Hageman factor, a novel sialoglycoprotein with esterase activity. Biochim. Biophys. Acta. 101: 166-176.

40. Kabat, E. A., K. O. Lloyd, and S. Beychok. 1969. Optical activity and conformation of carbohydrate. Biochemistry. $8: 747-756$.

41. Listowsky, I., S. England, and G. Avigad. 1969. An analysis of the circular dichroism spectra of uronic acids. Biochemistry. 8: 1781-1785.

42. Iizuka, E., and J. T. Yang. 1966. Optical rotatory dispersion and circular dichroism of the $\beta$-form of silk fibroin in solution. Proc. Natl. Acad. Sci. U. S. A. 55: $1175-1182$

43. Woody, R. W., and I. Tinoco. 1967. Optical rotation of oriented helices. III. Calculation of the rotatory dispersion and circular dichroism of the alpha and $33^{-}$ helix. J. Chem. Phys. 46: 4927-4945.

44. Gelman, R. A. 1974. Interactions of connective tissue mucopolysaccharides with collagen and model polypeptides. Ph.D. Thesis. Department of Macromolecular Science. Case Western Reserve University, Cleveland, Ohio.

45. Gelman, R. A., W. B. Rippon, and J. Blackwell. 1973. Interactions between chondroitin-6-sulfate and poly-Ilysine in aqueous solution: circular dichroism studies. Biopolymers. 12 : 541-558.

46. Saito, H., O. D. Ratnoff, J. S. Marshall, and J. Pensky. 1973. Partial purification of plasma thromboplastin antecedent (factor XI) and its activation by trypsin. $J$. Clin. Invest. 52: 850-861.

47. Speer, R. J., H. Ridgway, and J. M. Hill. 1965. Activated human Hageman factor (XII). Thromb. Diath. Haemorrh. $14: 1-11$.

48. Joly, M. 1965. A Physio-Chemical Approach to the Denaturation of Proteins. Academic Press, Inc., New York.

49. Tanford, C. 1968. Protein denaturation. Adv. Protein Chem. 23: 121-282.

50. Vroman, L., A. L. Adams, and M. Klings. 1971. Interactions among human blood proteins at interfaces. Fed. Proc. 30: 1494-1502.

51. Brash, J. L., and D. J. Lyman. 1969. Adsorption of plasma proteins in solution to uncharged, hydrophobic polymer surfaces. J. Biomed. Mater, Res. 3: 175-189.

52. Simmons, N. S., and A. N. Glazer. 1967. An analysis of the tyrosine circular dichroism bands in ribonuclease. J. Am. Chem. Soc. 89: 5040-5042.

53. Pflumm, M. N., and S. Beychok. 1969. Optical activity of cysteine-containing proteins. J. Biol. Chem. 244: 3973-3981.

54. Bush, C. A., and D. E. Gibbs. 1972. Aromatic sidechain cotton effects in cyclic hexapeptides. Biochemistry. $11: 2421-2427$.

55. Zeigler, S. M., and C. A. Bush. 1971. Circular dichroism of cyclic hexapeptides with one and two side chains. Biochemistry. 10 : 1330-1334.

56. Tiffany, M. L., and S. Krimm. 1968. New chain conformations of poly (glutamic acid) and polylysine. Biopolymers. 6: 1379-1382.

57. Rippon, W. B., and A. G. Walton. 1971. Optical properties of the polyglycine II helix. Biopolymers. 10 1207-1212. 
58. Wong, K.-P., and C. Tanford. 1973. Denaturation of bovine carbonic anhydrase $B$ by guanidine hydrochloride. A process involving separable sequential conformational transitions. J. Biol. Chem. 248: 8518-8523.

59. Armstrong, D. 1968. The effects of temperature on the response of human plasma kinin-forming system to promoting and inhibiting agents. $\mathrm{Br}$. J. Pharmacol. 34: $670-671$.

60. Weiss, A. S., Gallin, J. I., and A. P. Kaplan. 1974. Fletcher factor deficiency. A diminished rate of Hage- man factor activation caused by absence of prekallikrein with abnormalities of coagulation, fibrinolysis, chemotactic activity, and kinin generation. J. Clin. Invest. 53: $622-633$.

61. Walton, A. G., and J. Blackwell. 1973. Biopolymers. Academic Press, Inc., New York. 604.

62. Quadrifoglio, F., and D. W. Urry. 1968. Ultraviolet rotatory properties of polypeptides in solution. II. Poly-L-serine. J. Am. Chem. Soc. 90: 2760-2765. 